\title{
A Proposal of Both Use of Direct Moxibustion and Electro-Moxibustion for Cancer Treatment Moxibustion
}

\author{
Bong Kwan Jo', Soo Hyung Jeon ${ }^{2}$, Jong Won Kim² \\ ${ }^{1}$ Department of Electrical Engineering, Pukyoung National University \\ ${ }^{2}$ Department of Sasang Constitutional Medicine, College of Korean Medicine, Dong-Eui University
}

\begin{abstract}
Objectives: We here do propose that cancer treatment moxibustion should be used both direct moxibustion and electro-moxibustion simultaneously.

Methods: Electro-moxibustion is used in $38^{\circ} \mathrm{C}$ low-heat level and it will help to raise parasympathetic and to bring stability of mentality. Direct moxibustion is used in rice size and will help to raise sympathetic and to induce visceral reflection and visceral motion.

Results: Electro-moxibustion increased average body heat by $+2.51^{\circ} \mathrm{C}$ and kept patients from suffering pains. Direct moxibustion increased average body heat by $+1.2^{\circ} \mathrm{C}$ by meridian point-internal organs reflection.

Conclusions: Both use of direct moxibustion and electro-moxibustion simultaneously will be superior to the only either direct moxibustion or electro-moxibustion for cancer treatment moxibustion.
\end{abstract}

$\overline{\text { Key Words }}$ : Moxibustion, Sympathetic, Parasympathetic, Cancer, Hyperthermia

\section{Introduction}

The cancer treatments of Western medicine are mainly consisted with a surgical operation, radiation treatment, chemotherapy and immunotherapy, but now for the complementation to the limits of Western medicine the demands of alternative medicine are in explosive increase.

Yoon $\mathrm{HC}$ and his team investigated trends in treatment with and mechanism of moxibustion in cancer patients reviewed from domestic and foreign studies. They concluded in their study that moxibustion have the effects of immune improvement, tumor decrease, symptom reduction, and a reduction of adverse reaction of treatment, and that moxibustion studies to clinical cancer are in increase, and that Korea and China are in center. ${ }^{1)}$

Moxibustion therapy of Korean Oriental medicine is fit to improve hypothermia. The origin of direct moxibustion of Oriental medicine came from «Yellow Emperor's Inner Canon》. It was written in this book that the north is the end of earth, and high valley where people live, cold wind, the people like to live in fields, eat the milk products, they are to be hypothermia, the treatments for hypothermia is moxibustion. Therefore moxibustion came from the north. $^{2)}$

Hypothermia is a main factor of cancers. ${ }^{3)}$ Hypothermia is often occurs with aging. Thrombus is

\footnotetext{
- Received : 7 December 2017

- Revised : 22 December 2017

- Accepted : 22 December 2017

- Correspondence to: Jong Won Kim

Department of Sasang Constitutional Medicine, Dong-Eui University Korean Medical Hospital

282,Jungang-ro, Nam-gu, Ulsan, 44679, Republic of Korea

Tel : +82-52-226-8102, Fax : +82-52-226-0664, E-mail : jwonkim@deu.ac.kr
} 
a main factor of hypothermia. Stress also leads to hypothermia. But healthy children and young people tend to be in hyperthermia level.

Direct moxibustion of oriental medicine is a kind of hyperthermia of western medicine. But direct moxibustion is based upon 14 Meridian Theory. WHO (the World Health Organization) authorized the acupuncture and moxibustion in $1979^{4)}$ and 20 years examinations after WHO announced that the acupuncture and moxibustion could cure almost 300 diseases in 1998.

This study is aim to propose cancer treatment moxibustion. Cancer treatment moxibustion can be divided into 2 stages. The first stage is to soften the cancer pains, which can be approached by electro-moxibustion. And the second stage is to make the size of cancer smaller, which can be approached by traditional direct moxibustion.

\section{Subject and Methods}

\section{Direct moxibustion}

Direct moxibustion in oriental medicine is used as cancer treatment. Direct moxibustion burns the moxa on the skins of the meridians. Direct moxibustion influences the compositions of blood distinctively. For example, they are the different kinds of protein, the increase of white blood cells, and the production of heat shocked protein. They carry out the good roles for organic defense.

It is recently known that burn toxin by direct moxibustion, a different kind of protein, is a heat shocked protein (HSP). ${ }^{5)}$ HSP is the core function of direct moxibustion. HSP is in all living creatures. HSP has chaperone function, which controls activity and stability of cells. Chaperone function make immaturity cell to be matured, to be in charge of transportation in cells, and to involve the membrane transmission of cells by mitochondria. The chaperone function is used for cancer treatments and chronic

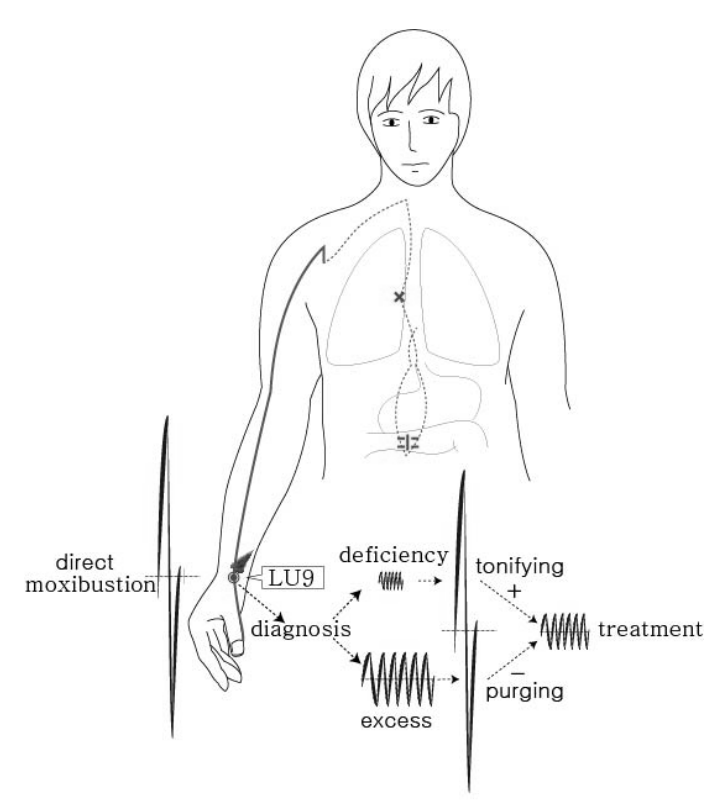

Fig. 1. Direct Moxibustion to Source Point LU9 (LU)

diseases. Also HSP makes covalent bond to the metaprotein of dying cells and works it to decompose with proteasome. Therefore HSP is a measure to estimate the Alzheimer's dementia. ${ }^{5)}$

Hyperthermia is used to improve immune system, and to cure cancer treatment. The cancer cells die in $42 \sim 43{ }^{\circ} \mathrm{C}$ temperature, and immunity increases 5 times with $+1{ }^{\circ} \mathrm{C}$ increase of body temperature. ${ }^{6,7)}$

Let's take an example. If there is a lung cancer, direct moxibustion is applied on the source point LU9 of lung meridian (LU). Moxibustion to source point induces impulse to lung meridian (LU), which helps better to circulate qi and blood among lung system. (Fig.1)

Table 1 is direct moxibustion experiment results from body heat thermograph before and after direct moxibustion on the 12 source points of 12 main meridians. IBR study permission on this study was acknowledged from Pukyong National University (document number: 1041386- 20160527-HR-011-03). The number of subject is 2 . (Table 1) 
Table 1. Results of Body Heat Variation by Direct Moxibustion on 12 Source Points

\begin{tabular}{|c|c|c|}
\hline & Before Direct Moxibustion & After Direct Moxibustion \\
\hline \multicolumn{3}{|c|}{ Case 1} \\
\hline & Mean Temperature $=30.10^{\circ} \mathrm{C}$ & Mean Temperature $=31.32^{\circ} \mathrm{C}$ \\
\hline \multicolumn{3}{|c|}{ Case 2} \\
\hline & Mean Temperature $=29.30^{\circ} \mathrm{C}$ & Mean Temperature $=30.36^{\circ} \mathrm{C}$ \\
\hline
\end{tabular}

Experiments were direct moxibustion to the 12 source points of 12 main meridians. Body heats were checked before and after for 1 hour's direct moxibustion with upper body off. In experiments all 2 cases showed $+1.22{ }^{\circ} \mathrm{C}($ case 1$)$, and $+1.06^{\circ} \mathrm{C}$ (case 2) increases of average trunk heat as shown in Table 1. These results indicated that direct moxibustion to source points makes body heat increased.

In oriental medicine there are source points upon arteries. Moxibustion to source point especially induces reflective stimulation to meridian vessel. The momentary scald of direct moxibustion induces meridian point-internal organs reflection. ${ }^{8,9)}$ at that time meridian point-internal organs reflection accompanies impulsive bioelectricity. Impulsive bioelectricity stimulates visceral nerves to reflect viscero-motors. Therefore the heat of internal organs increases owing to visceral motion.

Direct moxibustion makes no-breathing force in lower abdomen. Direct moxibustion stimulates sympathetic. $^{10)}$ this rise of the sympathetic nerve is to make internal organs exercised. Direct moxibustion makes the heat of internal organs increased and helps to keep them to be hyperthermia and help to activate cells. This is the key of direct moxibustion.

\section{Electro-moxibustion}

1) Structure, operations and anticancer mechanism An example of electro-moxibustion (Fig. 2) is constructed with the infrared ceramic heating device which composition is $\left(\mathrm{Ba}_{0.8} \mathrm{Sr}_{0.2}\right)_{0.996} \mathrm{Y}_{0.004} \mathrm{TiO}_{3}+$ $0.5 \%{ }_{\mathrm{wT}} \mathrm{SiO}_{2}$ and with the moxa-extraction pad which 


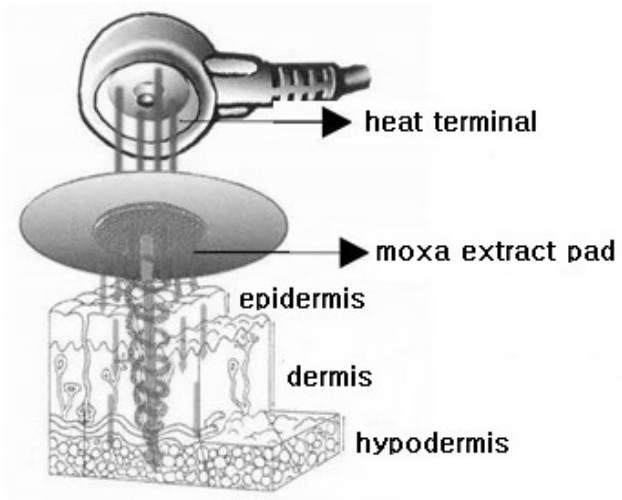

Fig. 2. An Example of Electro-Moxibustion

is the aim for drug-delivery-system (DDS) through the skin. ${ }^{11)}$ Electro-moxibustion can generates heat to maintain the skin temperature between $38^{\circ} \mathrm{C}$ (low-level) and $49^{\circ} \mathrm{C}$ (high-level). A cancer is a chronic disease with pain. To remove from pain in cancer patients can be carried out by electro -moxibustion. $38^{\circ} \mathrm{C}$ heat is in low- level in electro-moxibustion. Though high -level heating stimulates sympathetic, low-level heating stimulates the rise of parasympathetic. Therefore $38^{\circ} \mathrm{C}$ low-level electro-moxibustion makes the rise of parasympathetic only.
2) Body heat variation experiments by electro -moxibustion on abdomen

Experiment was electro-moxibustion to abdomen for 1 hour. Body heats were checked before and after, and 3 times every 2 hour's interval. For thermography, adaptation time was 10 minute. ${ }^{12)}$ This experiment showed $+2.02{ }^{\circ} \mathrm{C}$ maximum increase of average trunk heat after 4 hour as shown in Fig. 3.

3) Body heat variation experiments by electro -moxibustion on CV4, CV8 and CV12

Experiment was electro-moxibustion to CV4, CV8 (the navel), and CV12 for 1 hour. Body heats were checked before and after, and 2 times for 2 hour's interval. For thermography, adaptation time was 10 minute. ${ }^{13)}$

This experiment showed $+2.51{ }^{\circ} \mathrm{C}$ maximum increase of average trunk heat after 4 hour as shown in Fig. 4.

Cancer has pain. Electro-moxibustion gets rid of the inflammatory substance of cancer and alleviates the pain of cancer. Ohsawa ${ }^{14)}$ and his team worked on heat stimulation using electro-moxibustion and stated in the study that the heat decomposition substance absorbed in blood by moxibustion leads to

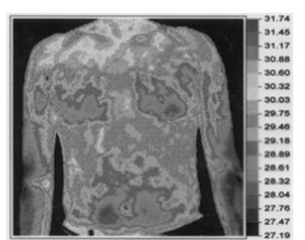

Before Electric Cauterization

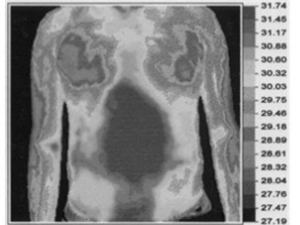

Just Stimulation

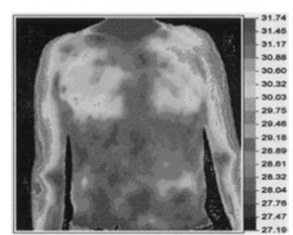

After 4 hours

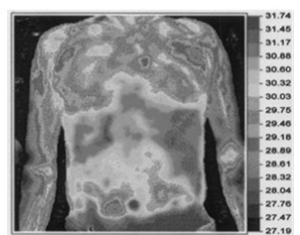

After 2 hours

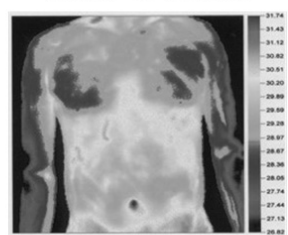

After 6hours

Fig. 3. Heat Variations Before and After Electro-Moxibustion on Abdomen

a treatment function for pain and named this 


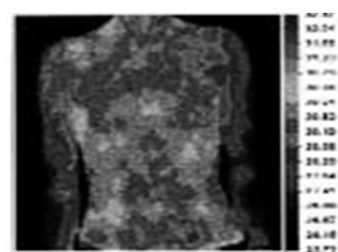

Prestimulation

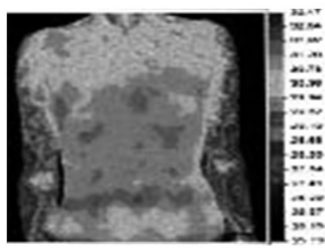

After 2 hours

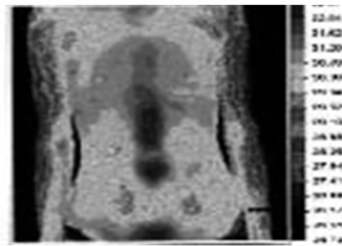

Just Stimulation

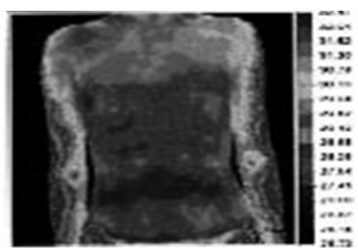

After 4 hours

Fig. 4. Heat Variations Before and After Electro-Moxibustion on CV4, CV8 and $\mathrm{CV}_{12}$

antihistaminic substance "histotoxin". There is a clinical study that a patient suffering from lung cancer was improved by indirect moxibustion treatment. ${ }^{15)}$

\section{Results}

In moxibustion experiments, the heat of abdomen were increased by $+1.2^{\circ} \mathrm{C}$ in direct moxibustion and by $+2.51{ }^{\circ} \mathrm{C}$ in electro-moxibustion. We evaluate that heat increment by direct moxibustion has more importance in heat variation than electro-moxibustion since direct moxibustion is applied to source points in wrists and in ankles apart from abdomen but electro-moxibustion is applied to abdomen directly.

In direct moxibustion there are sharp scalds in operation, and it makes no-breathing abdominal regional force to increase sympathetic. The pause of direct moxibustion recovers parasympathetic. Therefore direct moxibustion induces the motion of internal organs by source point-internal organs reflection to increase the heat of internal organs. Those phenomena of sympathetic increment did not occur in electro-moxibustion radiating $38^{\circ} \mathrm{C}$ low-level heat.
But indirect moxibustion radiating $38^{\circ} \mathrm{C}$ low-level heat makes the rise of parasympathetic to bring stability of mentality. ${ }^{16,17)}$

We propose that cancer treatment moxibustion use both traditional direct moxibustion and electro -moxibustion simultaneously. In proposed cancer moxibustion electro-moxibustion is used to the regions of the cancer pain, and direct moxibustion is used to source points. For example, proposed cancer moxibustion is applied to lung cancer (Fig. 5). Pains from lung cancer occur in LU1, BL13. These points can be treated by electro-moxibustion to get rid of pain. Meridian points to treat the lung cancer are the source points LU9 of lung meridian (LU) and the connecting points LI6 of large intestine meridian (LI). Cancer can be treated by direct moxibustion to induce the sympathetic rise and visceral motors, which makes internal organs hyperthemic level.

\section{Considerations}

Electro-moxibustion is useful to treat chronic diseases without scalds. Diabetics prefer electro -moxibustion to direct moxibustion because of scalds 


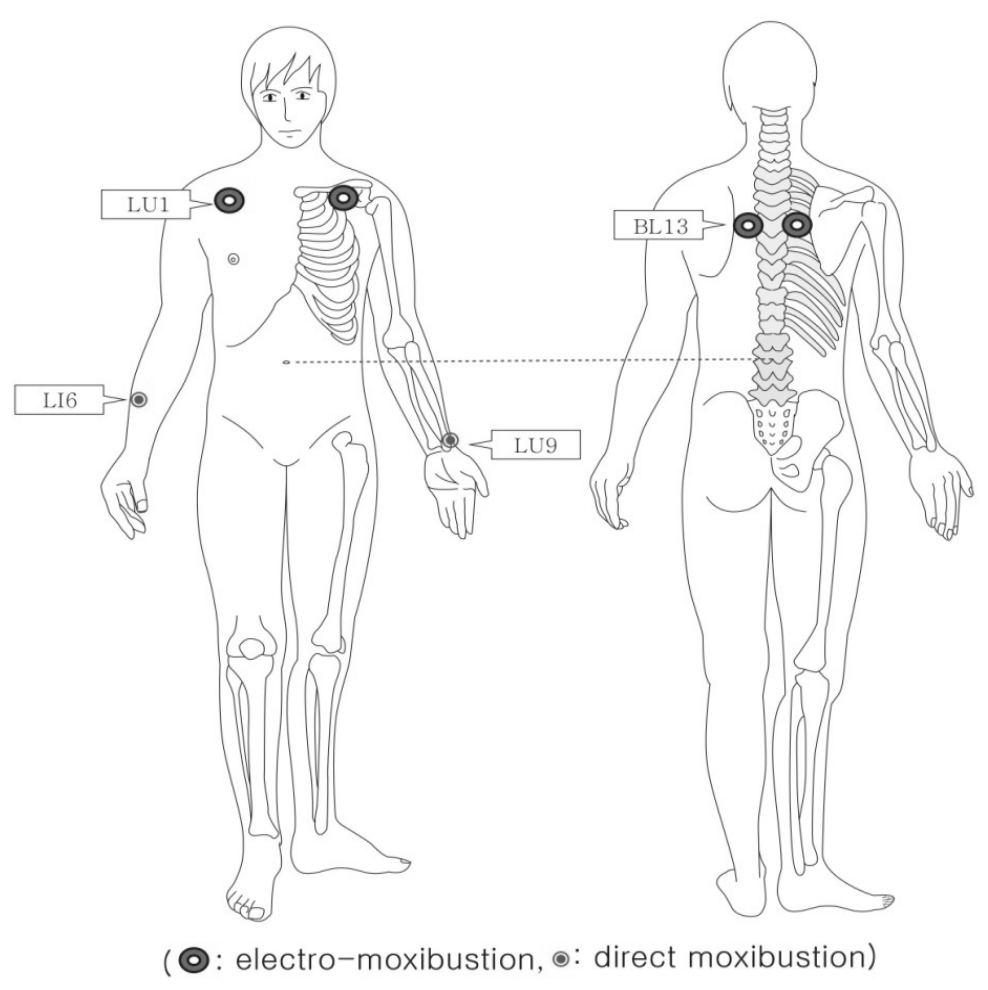

Fig. 5. An Example of Lung Cancer Treatment Moxibustion

and adverse reaction. Kim JW and his team treated diabetics electro-moxibustion and presented a clinical study about it. ${ }^{18)}$

Hyperthermia is currently highlighted as the 4th cancer treatment with the surgical operation, radiation treatment, and chemotherapy and frequently treated to breast cancers. ${ }^{19-21)}$

Better blood flow brings cells more oxygen and nutrients to build immune system easily. And only $1{ }^{\circ} \mathrm{C}$ increase of body temperature makes bone cells strong to prevent osteoporosis. Increase of body temperature makes better blood flow, which induces good influences in peristalsis of digestive organs. Better peristalsis gets rid of the formation of enterotoxin to help preventing colon cancer.

Kanai $^{22}$ and his team stimulated electro -moxibustion in ovariectomized rat model. Before electro-moxibustion the ovariectomized rat showed hypothermia. Moxibustion to the ovariectomized rat showed heat increased to improve hypothermia.

Cancer cells tend to increase in hypothermia. ${ }^{2,677)}$ Saito ${ }^{7)}$ presented that cancer cells readily were propagated in hypothermia, which is the reason that cancer cells are propagating in anaerobic metabolism. Transformation from normal cells to cancer cells is caused by the destruction of aerobic metabolic mitochondria. It is a strong advantage for cancer patients to increase body temperature. While body heat keeps in $37^{\circ} \mathrm{C}$ level, natural killer cells destroy cancer cells more actively.

There is a study on the effect of moxibustion on dopaminergic and serotonergic system of the nucleus. In this study moxibustion has an alleviation effect of pain and moxibustion has a possibility for preventing 
and curing the Alzheimer's dementia. ${ }^{23)}$

\section{Conclusions}

Cancer would be inevitable in the long run as human live long. Even though human recovered completely from cancer, the relapse risk of cancer still remains with aging.

In this study cancer treatment moxibustion that both direct moxibustion with electro-moxibustion should be simultaneously treated is proposed .Direct moxibustion makes the rise of sympathetic to induce source point-internal organs reflection and to induce internal organs exercised and to make the heat of internal organs increased. $38^{\circ} \mathrm{C}$ low-level Electro -moxibustion makes the rise of parasympathetic owing to bring stability of mentality. Both direct moxibustion and electro-moxibustion make the body heat by $+1.2^{\circ} \mathrm{C}$ and $2.5^{\circ} \mathrm{C}$ increased.

Only use of direct moxibustion or electromoxibustion as cancer treatment moxibustion is inferior to both use of direct moxibustion and electro- moxibustion for autonomic nerve balance.

Moxibustion in Oriental medicine is a traditional cancer treatment without adverse reaction, self-curing from pain, no expense, with dignity, most acceptable.

\section{Acknowledgments}

This work was supported by a Research Grant of Pukyong National University (2016 year).

\section{References}

1. Yoon HC, Kang JY, Kim JY, Jeong JY, Son $\mathrm{CG}$, Lee NH, et al. Trends in Treatment with and Mechanism of Moxibustion in Cancer Patients: A Review. Korean J. Orient. Int. Med. 2015; 36(3): 361-79.

2. Yamada KY, Siroda BG. Oriental Medicine. $1^{\text {st }}$ rev. ed. Seoul: Nonjang. 1992:48-9
3. Han S, Hwang WJ, Keum KS, Lee SH. Effect of hyperthermia on the cancer. JPPKM. 2006; 20(5):1135-48.

4. Lee BK. Acupuncture and moxibustion therapies authorized by WHO. $1^{\text {st }}$ rev. ed. Seoul: HyundaiChimguwon. 1991:1-3.

5. Kobayashi K. Induction of heat shock protein by moxibustion. American J Chinese medicine. 1995;23:327-30.

6. Nobuhiro YM. $1{ }^{\circ} \mathrm{C}$ hyperthermia wins the cancer. $1^{\text {st }}$ rev. ed. Seoul: Seren DPT. 2015:59-61.

7. Saito M. $+1^{\circ} \mathrm{C}$ body heats save my body. $1^{\text {st }}$ rev. ed. Seoul: Narawon. 2012:53-55.

8. Isikawa T. Viscera skin reflection. $1^{\text {st }}$ rev. ed. Tokyo: Igakushoin. 1962:13-20.

9. Serizawa K, Mori W, Nishizhou I. Studies of Meridians and points: Study collections of Oriental medicine 1. Tokyo: Ichigusurishupankabusikikaisha. 1979:278-88.

10. Nishizhou I. Heart rate decrease response and autonomic nerve reflections by acupuncture stimulation. J Japan Oriental Med. 1990;6(1): 33-41.

11. Jo BK (Inventor), Kijang Medical Co. Pusan (KR) (Assignee). Method of Preparing Phamacheutical Moxa Extract and Apparatus for Electrical Moxibustion Using the Same Extract. Jun.26. 2001: US Patents 6,253,104 B1.

12. Jo BK, Yoon DE, Kim JP, Kong GH, Kim ES, $\mathrm{Kim} \mathrm{HY}$, et al. Experimental estimation of the effect on the body heat by electro-moxibustion and the moxa-lotion. Proceeding of IEEE-EMBS ASIA-PACIFIC Conference on biomedical engineering. 2000:743-4.

13. Jo BK, Yoon DE, Choi YR, Seo JP, Kong GH, Kim ES, et al. Implementation of the moxa-pad moxibustion cauterizer with the Single Heating -pad \& the Multiple Heating-pad. IEEE International Symposium on Industrial Electronics Proceedings. 2001:590-5.

14. Noguchi E, Ohsawa H, Takegi K. Neural 
mechanism of localized changes in skeletal muscle blood flow caused by moxibustion-like thermal stimulation of anesthetized rats. J Physiol Sci. 2009;59(6):421-7.

15. Kim MK, Lee JS, Lee SH, Jung HS, Choi WC, Kim KS. A Clinical Case of Patient with Cancer Pain Treated by Moxibustion. J of Kor. Traditional Oncology. 2009;14(1):53-9.

16. Kim OH, Choi JE, Yoon JW, Yoo HS. The Effect of Moxibustion on Heart Rate Variability in Cancer Patients. J of Kor. Traditional Oncology. 2011;16(1):15-31.

17. Park DH. A Study on the Variation of the EEG by the Moxibustion Stimulation on Oriental Medicine[Master' degree thesis] Pusan:DongEui University;2008.

18. Yoon DE, Jo BK, Bae JI, Gu JS, Kim JW, Lee HM, et al. A Study on the Variations of Trunk Temperature and Clinical Test for Diabetics by Artemisia Extract Moxibustion Method. J Korean Oriental Med. 2006;27(1):165-183.

19. Zagar TM, Oleson JR, Vujaskovic Z, Dewhist
MW, Craciunescu OI, Blackwell KL, et al. Hyperthermia for Locally Advanced Breast Cancer. Int. J Hyperthermia. 2010; 26(7): 618-24.

20. Noguchi E, Ohsawa H, Takegi K. 2009, Neural Mechanism of Localized Changes in Skeletal Muscle Blood Flow Caused by Moxibustion-Like Thermal Stimulation of Anesthetized Rats. J Physiol Sci. 2009:59(6);421-7.

21. Calderwood SK. Heat Shock Protein in Breast Cancer Procession. Int. J Hyperthermia. 2010; 26(7):681-5.

22. Kanai S, Taniguchi N, Kanda K, Matsuhata I. Study of Moxibustion Stimulation in the Ovariectomized Rat Model. OPEM. 2005;5(3): 195-200.

23. Fukuda H, Shinbra H, Yoshimoto K, Yano $\mathrm{T}$, Kuriyama K. Effect of Moxibustion on Dopaminergic and serotonergic system of nucleus accumbens. Neurochemical research. 2005; 30: 1607-16. 